\title{
IT and Computer Technologies for Education of Senior Citizens and Improving the Quality of Their Life
}

\author{
Olga A. Anikeeva ${ }^{1 *}$, Valeriya V. Sizikova ${ }^{1}$, Tatiana E. Demidova ${ }^{1}$, Larisa I. Starovojtova ${ }^{1}$, \\ Anna G. Akhtyan ${ }^{1}$, Regina B. Godzhieva ${ }^{1}$, Anastasia V. Karpunina ${ }^{1}$, Zhumagul A. Maydangalieva ${ }^{2}$ \\ ${ }^{1}$ Russian State Social University, Moscow, RUSSIA \\ ${ }^{2}$ S. Baishev Aktyubinsk University, Aktobe, KAZAKHSTAN
}

Received 21 November 2018 - Revised 21 March 2019 - Accepted 27 March 2019

\begin{abstract}
At present, IT have become an indispensable condition for the quality of education, but they are rarely applied in education of senior citizens and their range is quite narrow. An exception is the methods of teaching computer literacy to older adults, which is much narrower than IT in education. Meanwhile, they are no less essential both for adaptation of the elderly to the contemporary conditions of life and for the young generations. The authors prove that application of these technologies can change the quality of life for older adults and enables them to extend their professional activity, to broaden their scope of communication, and to raise their level of social adaptation to the environment and daily life. It has been found during the research conducted that the use of IT in education of senior citizens has some essential features and requires special conditions of application. In the research, questionnaire survey and testing, indepth interview, expert survey, and participant observation methods were used that allowed studying the senior citizens' demands for educational services, computer literacy improvement, as well as barriers and risks in their getting the education, conditions for enhancing its efficiency. During the research, disadvantages in development of IT and software products targeted for education of the aged have been found. The results obtained allow contributing to the development of concepts of thriving old age, active longevity, and higher social and professional engagement of older adults. They are of great importance both for the very senior citizens and for education providers, as well as for developers of educational software products needed by older adults and their teachers.
\end{abstract}

Keywords: IT in education, information literacy, senior citizens, education of senior citizens, quality of life of senior citizens, software products for education

\section{INTRODUCTION}

Information and computer technologies are changing the world of education. Computer automation of education includes the material and financial part and the technology-related one. The material and financial part implies the opportunity of having a computer or the access to computers and gadgets that can perform educational functions (having educational software). This is a decisive condition that not all regions of Russia can ensure - there are remote areas where this has been impracticable so far. However, most Russian older adults are already acquainted with computers and have "teachers", as a rule, relatives - their children and grandchildren. The second condition of computer automation - the technological one - implies the availability of programs and the appropriate educational IT. Their composition gets changed, and it expands the opportunities of education and can improve its quality, too. However, the scientific literature mainly deals with IT in school and professional education.

(C) 2019 by the authors; licensee Modestum Ltd., UK. This article is an open access article distributed under the terms and conditions of the Creative Commons Attribution License (http://creativecommons.org/licenses/by/4.0/).

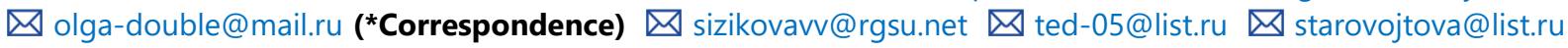

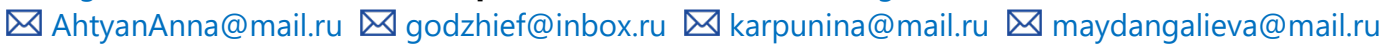




\section{Contribution of this paper to the literature}

- The authors suggest: 1) developing an entire range of software products that allow increasing the efficiency of learning in senior citizens. These can be gaming software for practicing the skills in professional activity or obtaining the information on some relevant legal advice questions, or working on the state services website, ordering railway and air tickets, searching for the necessary information of cultural and leisure nature; 2) making broader use of computer technologies (in particular, communicating via Skype) in the activity of social service centers and social work specialists enabling them to consult citizens online; 3 ) applying IT for visual express diagnostics of the senior citizens' psychological condition and for more precise monitoring of their psychological well-being; 4) applying IT for establishing network communications and creating mutual communication assistance groups of the aged.

- It is proven in the paper that: 1) the use of IT in education of older adults and their mastering computer literacy can change the senior citizens' quality of life and enhance their well-being; 2) computer literacy gives an opportunity to prolong professional activity of the aged so that they remain sought-for at the labor market with their special resources of professional activity; 3) mastering computer literacy and the use of IT broadens the communication scope of the elderly, raises the level of their social adaptation to the environment and daily life, helps overcome the psychological loneliness problems, and mitigates isolationism in relation to senior citizens.

Education for the aged has a threefold function to perform. First, it is a part of the lifelong learning system, most notably, the professional education one. The world is changing rapidly, and accumulation of new professional activity technologies urges for continuous update of professional skills and competencies. The more difficult a profession is, the more it is related to other occupations and it is fulfilled in complicated social interrelations. Therefore, the system of further professional education or professional retraining has to be consistent and specialized, targeted at particular demands. For senior citizens, this is as important part of life as it is for other age groups, but it faces certain difficulties and obstacles.

The second function is that of general socialization. As people age, it is not only the conditions of their professional life but also all life activity conditions that change. So, everything - from plain and simple daily functions up to adaptation in their community, grasping the social processes unfolding in the world - needs additional knowledge and skills.

The third function, the sociocultural one, helps senior citizens not only adapt in the world around them but also turn to interests and needs not yet fulfilled, to active leisure or public activity, to social volunteering, perhaps.

All the three functions require organizing a large-scale and stable education institution for older adults.

Meanwhile, it has to be borne in mind that as people age, their memory, attention, speed of thinking, the capacity of perceiving and remembering the new information, of shaping new skills and improving already available ones go down. Certainly, this does not apply to each and every aged person; it is with age that many of them reach the top of their professional form. However, the majority of older adults being in question, they need special educational technologies, including IT and special software products.

The international Global Age Watch Index conducts assessment the senior citizens' quality of life in 96 countries of the world (Online. Available: https://countryeconomy.com/demography/global-agewatch-index) using the statistical analysis of 13 dynamic indicators. Among them, educational needs and opportunities of satisfying them are adopted as basic indicators of the quality of life of the aged.

Thus, meeting the educational needs of the older generation citizens is currently becoming one of the pillars of social welfare of the society in general and of the entire social and age group of older adults, in particular. The factor matters in every respect: in the economic, social and sociocultural ones. It is studying the senior citizens' educational needs and ways for satisfying them and developing IT and software products for this kind of education that is the paramount social task of the contemporary society. The influence of education on social well-being of the older generation citizens is of great theoretical and applied importance.

The research conducted by the authors is dedicated to studying the relevance of education of the aged in the contemporary society and the opportunities for applying IT in this focus area. Using the conventional research methods of both theoretical and applied nature allowed making some conclusions that matter for organization, technological and software support of the senior citizens' education.

\section{LITERATURE REVIEW}

The literature dedicated to the research topic can be subdivided into three groups. The first one studies the particularities of IT and computer technologies in education (Gavrilyuk, Sorokin, \& Farakhutdinov, 2009; 
Ismaghilova \& Nabiullina, 2017; Kuzmin \& Parshakova, 2017; Mamedova, 2016; Morozova, 2012). The same subject within the context of continuing education is addressed by Horrigan, Rainie and Page (2016).

The second group of researchers analyzes the risks that can be overcome by expanding the range of information and computer education - first of all, the risk of infantilization of the elderly in the contemporary society (Miklyaeva, 2018; Marson, 2013; Marson \& Powel, 2014).

The third group is the most numerous. These studies deal with problems of the aged and improving the quality of their life, in particular, by means of education. Arnett (2011) and Bowling (2007) study the sociocultural foundations of the new concept of ageing. Komp and Van Tilberg (2010) analyze the questions of ageing of the society and ones of the quality of life of the contemporary society, and Kohli (2005) - the questions of links between generations and the opportunities for mutual understanding in the information society.

Foreign researchers point out the importance of information literacy of the elderly for improving the quality of their life, increasing the duration of professional and creative activity, as well as for enhancing their social and psychological well-being (Mcnamara \& Williamson, 2004; Moody, 2001; Moulaert \& Biggs, 2013). This topic is quite of interest with the Russian scientists, too (Aslanova, 2011; Chigisheva, 2018; Gasanov, 2015; Kondratov, 2009; Salimyanova, 2013; Smolkin, 2012).

In this group, an individual place belongs to works discussing the senior citizens' information literacy (Akhtyan et al., 2018; Anikeeva, Sizikova \& Fomina, 2017; Azarina, Bulozerskikh, \& Venevtseva, 2011; Bogdanovskaya, 2014; Kozlovskaya et al., 2018; Naumov, 2015). There are works analyzing the competence level of older adults (Podolskiy, Popov, \& Rylko, 2015) and their position at the labor market (Vladimirov, 2015).

So, it can be seen that there are quite a few works associated with the problems range of the research. However, the questions of special IT, their specific character in what concerns the senior citizens' education, as well as software products designed particularly for ensuring this activity are extremely underexplored.

\section{MATERIALS AND METHODS}

Theoretical methods used in the research included functional and typological analysis as well as the methods of comparative and systemic analysis. This is highly important as each social phenomenon has to be studied from different perspectives in the total of all conditions and factors influencing it. The methods of applied research included questionnaire survey in the form of a pilot poll, with $\mathrm{N}-58$ (30 women aged 55 to 82 , the age subgroups being 55-70 years old and 71-82 years old; 28 men aged 60 to 83, their subgroups being 60-70 and 71-83 years old). Among the surveyed ones, there were 36 people having the higher education, 16 - the secondary vocational one, and 10 people having no special education, including the social service workers having no professional education. The sample is defined as the quota random one. In-depth interviews aimed at making more precise the understanding of difficulties faced by senior citizens in the process of education were conducted with 8 respondents.

The methods of participant observation performed by teachers providing educational services for the elderly and expert survey of the teachers were employed too. The methods of analyzing the data obtained as a result of other authors' studies (secondary data analysis) were used in processing the data.

The research was conducted in Russia, Moscow region, incorporating the metropolitan city of Moscow and Moscow region itself, in November, 2017 - March, 2018.

The research hypothesis relies on assumption that in education of older adults, special IT and software are needed corresponding to social and psychological particularities of their age, as well as their educational demands.

The objective of the research was to study the opportunities for improving the efficiency of education of senior citizens and ultimately - the quality of their life by means of educational services.

In the process of verifying the hypothesis worded, the following tasks were set: to study educational needs of older adults, including their demand for computer education, and any obstacles in fulfillment thereof; to analyze conditions for improving the efficiency of education of the aged using IT and computer educational technologies; to identify the most sought-for information technologies and the teachers' demand for new software products providing educational process support for senior citizens.

\section{RESULTS}

First of all, the basic definition of computer literacy and IT in education that was used by the authors when conducting the research should be given. Computer literacy was evaluated as an umbrella term that encompasses teaching skills of working with the computer to users, information literacy (i.e. a set of competencies that are necessary for obtaining, understanding, evaluating, adapting, generating, storing and representing the information used for analyzing problems and decision-making), skills of working with information and bibliographic skills 
Table 1. Purposes of gaining the skills of working with the computer

\begin{tabular}{clc}
$\begin{array}{c}\text { Item } \\
\text { No. }\end{array}$ & Purposes of gaining the skills of working with the computer & $\begin{array}{c}\text { Share in the } \\
\text { answers }\end{array}$ \\
\hline 1. & For getting in touch with friends and making new friends, within social communications & $92,3 \%$ \\
\hline 2. & $\begin{array}{l}\text { For mastering the necessary professional computer skills, continuing the professional activity and } \\
\text { enhancing one's being sought-for at work }\end{array}$ & $76,9 \%$ \\
\hline \multirow{2}{*}{$\begin{array}{l}\text { For keeping one's vitality, rendering leisure more full-fledged, broadening one's outlook, satisfying one's } \\
\text { cognitive and general cultural interests }\end{array}$} & $73,0 \%$ \\
\hline 4. & For drawing up various documents of social nature (benefits, compensations etc.) & $71,1 \%$ \\
\hline 5. & For ordering certificates and documents, for working on the state services website & $69,9 \%$ \\
\hline 6. & For developing one's abilities, for practicing hobbies & $28,8 \%$ \\
\hline
\end{tabular}

(operations with information and transforming it), skills of using software products of various purpose and levels (educational and professional programs), skills of searching for and verifying the validity of information required in various spheres of life activity, and fluency of the said skills. The demand for these skills was studied by the authors during the research.

Information technologies in education involve using digital educational resources (digital lectures, reference and information materials for educational courses, cases for individual assignments); applying the computer simulators and virtual laboratory works as well as software products aimed at practicing the fluency and precision of the work skills. These are digital funds of assessment means used for checking the learners' knowledge, too; the use of multimedia and interactive board in the process of teaching; the use of distance learning and online education technologies, remote consulting work.

Computer education and outreach in Russia are entrusted to social service organizations, and this is the reason why the research was conducted with the assistance of two local centers. In Moscow, it was the state budget-funded institution "Tsaritsynskiy community-based center". In Moscow region, the research was based on the state budgetfunded social service institution of Moscow region "Pushkinskiy integrated center for social service of the public". Moscow region was the option for the research as it is one of the most advanced in terms of technical provision and the use of IT in education and learning of older adults. This is confirmed by the regional program "Moscow longevity", in the course of which citizens of Moscow had an opportunity to broaden their competencies, to master computer literacy and get a wide range of educational services of the most diverse focus. The community-based centers were contracted for performing research activity, monitoring the quality of social service, the expert and analytical activity. According to the contract signed, the object of the research was two groups. The total quantity of the respondents amounted to 58 people, including 30 women aged 55 to 82, the age subgroups being 55-70 years old and 71-82 years old, and 28 men aged 60 to 83, with the 60-70 and 71-83 years old subgroups. Among the surveyed ones, there were 36 people having the higher education, 16 - the secondary vocational one, and 10 people having no special education, including the social service workers having no professional education. All respondents studied the fundamentals of computer literacy. The research conducted was of pilot nature, it was necessary for verifying the working hypotheses and subsequently developing a larger scale study.

During the questionnaire survey, answers were obtained to questions about how important for the respondents the skills of working with the computer were. The absolute majority of the surveyed ones have a computer and gadgets at home $(92.3 \%)$, most have an experience of working on the computer $(73.1 \%)$, and computer working skills are always required for $63.5 \%$ of the respondents. $11.3 \%$ rarely turn to working on the computer and only $1.9 \%$ do not need such skills. For the Russian reality, the following sources of obtaining knowledge and skills are characteristic: the most frequently, these are relatives (32.7\%), fellow workers $(23.1 \%)$, friends $(15.4 \%)$ and it was only $15.4 \%$ who gained the knowledge from professionals at special educational centers. This means the majority of the respondents have an incomplete, fragmented and non-professional knowledge, as a consequence of which, their skills are often insufficient and need correcting and supplementing.

The answers in Table 1 were obtained for the question about the purposes for which the respondents use their skills of working with the computer.

In particular, $23.1 \%$ of the respondents said they were not interested in obtaining further education and mastering computer technologies: either for the reasons of those being not sought-for in their jobs, or due to their being quite busy in the family and household. As for $15.4 \%$, they just do not consider it interesting for them. As a rule, they are senior citizens aged over 65 , with men prevailing among them.

According to the forms of obtaining the education, the answers were distributed as shown in Table 2. 
Table 2. The sought-for form of educational services

\begin{tabular}{ccc}
\hline $\begin{array}{l}\text { Item } \\
\text { No. }\end{array}$ & What form of educational activity are you interested in? & $\begin{array}{c}\text { Share in the } \\
\text { answers }\end{array}$ \\
\hline 1. & The formal one (with a document to be issued to certify further training or mastering the competencies) & $76,9 \%$ \\
\hline 2. & The informal one that is required for satisfying educational needs & $73,0 \%$ \\
\hline 3. & Various forms & $53,8 \%$ \\
\hline 4. & I am not interested in any of them & $15,4 \%$ \\
\hline
\end{tabular}

Table 3. Obstacles to obtaining educational services

\begin{tabular}{|c|c|c|}
\hline $\begin{array}{l}\text { Item } \\
\text { No. }\end{array}$ & Causes preventing people from getting educational services & $\begin{array}{l}\text { Share in the } \\
\text { answers }\end{array}$ \\
\hline 1. & I have no opportunity because I am busy at work or in household chores. & $73,0 \%$ \\
\hline 2. & There are not enough distance-learning resources for the employed ones. & $73,0 \%$ \\
\hline 3. & There is not enough information about the educational resources. & $69,2 \%$ \\
\hline 4. & My employer is not interested in further training. & $53,8 \%$ \\
\hline 5. & There are educational resources but I do not know how to address them. & $53,8 \%$ \\
\hline 6. & The main obstacle is the absence of the courses I need. & $34,6 \%$ \\
\hline 7. & The timetable of classes at social service centers is not comfortable. & $23,1 \%$ \\
\hline 8. & No, there are no obstacles; it all depends on my wish only. & $9,6 \%$ \\
\hline
\end{tabular}

When raising their self-education level, the respondents turn to the Internet sources (73.0\%), take part in educational activity in intramural groups (30.8\%) or visit single lectures (or cycles of lectures), workshops and seminars $(23.1 \%)$, while distance learning is preferred by $15.4 \%$ of the respondents. (Table 3)

Thus, the questionnaire survey has shown that the demand for educational services is very high, and so is the importance of such education. Most respondents clearly associate improving their education with the quality of their life. This is relevant both for working older adults and for those who have already retired, with computer education taking the central place in any of the options.

The in-depth interview conducted at the same time as the questionnaire survey has shown that in today's Russia, the prestige of education is very high at any age. However, there are numerous obstacles: from the senior citizens' being quite busy and so merely having no time to get education up to the obstacles related to their being informed poorly about the opportunities of getting education. It cannot but be seen that there are complaints about the quantity and composition of educational programs of distance learning, online courses, including those adapted to the interests of older adults.

The in-depth interviews and expert survey of specialists organizing educational courses for senior citizens have revealed some psychological particularities and obstacles in education of the aged.

Difficulties mastering the conceptual framework of computer literacy were ranked first both by experts and the very respondents. Younger teachers have to take into account that the advanced youth slang is not clear to the older generation. Explanations should be given and special dictionaries should be developed that could explain the main terms to senior citizens in an accessible form.

The second obstacle is compromised memory. In order to consolidate the obtained knowledge and skills, older adults need some more time and repetitions of the actions. In this respect, the aged clearly need practice software developed that is aimed at reinforcing even the simple skills: filling in their personal details, filling out application forms on the state services portals etc. The older adults' particular psychological apprehension of digital devices has to be taken into account, too. It can be overcome using the simplest tutorials; however, none have been developed so far.

The third obstacle is a greater than in the young ones need of working individually, being controlled and corrected individually. At the same time, no training of teachers for working exactly with senior citizens is being conducted. So their pedagogical skills are not adapted to the age-related particularities of older adults.

The fourth obstacle named by the experts concerned their professional toolkit. It is the evident lack of auxiliary digital resources and software support for information technologies in education of the aged. The fund of digital educational resources, courseware, electronic textbooks, gaming and testing software etc. is insufficient. Just like other age groups, senior citizens perceive the information better if there are visualized courses; however, even for children and youth, there are not enough such computer literacy video courses. It is for the elderly that distance classes allowing them to watch the material repeatedly could be quite helpful. Moreover, distance classes could be a significant saving of the teachers' time and effort and they could also make use of opportunities of those older adults who continue working and cannot spare enough time for education and self-education. 


\section{DISCUSSION}

This problem is viewed from various standpoints in the scientific and educational literature. The conceptual framework is suggested in the work of Pashchenko (2013); it allowed identifying the main software products lacking in educational work with the aged. The digital magazine "Peterburgskaya pensionerka" (Eng. "St Petersburg lady in retirement") has offered a brief video course of lectures in computer literacy. This is a unique course based on using IT (Simple technologies). The importance of computer literacy and the use of information technologies is confirmed by the state policy: in March 2005, the federal-level project "IT penetration of the education system (IES)" was launched in Russia, and 2008 saw the completion of fulfillment of the project "IT penetration of the education system (IES)" by the National Training Foundation (NTF). One of the results of the project was the creation of the United collection of digital educational resources (CER). However, all these resources are targeted at youth to a greater extent.

As for the elderly, information technologies in social service of senior citizens have been studied (online consulting, communication of specialists with those in their care via Skype, which allowed visually evaluating the condition and psychological vitality of senior citizens receiving social service (Firsov \& Shimanovskaya, 2018; Ilyina et al., 2017). These technologies and methods of social work also depend on the older adults' level of computer skills.

It is quite important, too, that the results obtained definitely correspond to studies of the foreign authors. Studying the preferences, objectives and attitudes of the American senior citizens shows they are very similar to the interests and demand of the Russian older citizens. $73 \%$ of adults consider themselves to be lifelong learners, $55 \%$ of the American employees are interested in improving their professional competencies, $36 \%$ would like to get education for certifying their new professional skills and so on (Horrigan, Rainie, \& Page, 2016).

\section{CONCLUSION}

The contemporary world's conditions of life urge all population groups to make use of computer technologies. While in the general education there are curricula to provide for teaching computer skills, older adults' learning needs special efforts, special organization, employing the adapted IT, developing and applying specialized software products.

According to the research conducted, it has been found that the demand for computer literacy is fairly high, although not all senior citizens are prepared for and interested in mastering the skills of working with the computer. In terms of functioning, it is the communication expansion opportunities that are the most sought-for. This conclusion is confirmed by observations of social work specialists and psychologists who identify loneliness and lack of communication in older adults as one of the most urgent problems in this age group. It can be supposed that a broader use of computer technologies (in particular, communicating via Skype) has to be made in the activity of social service centers and social work specialists both for improving the citizens' psychological well-being and for visual express diagnostics of their psychological condition. Special information technologies can be applied for establishing network communications and creating mutual communication assistance groups of the aged.

A conclusion was also made to the effect that professional retraining of senior citizens who go on their professional activity is not sufficiently sought-for. The cause may consist in the employers and the very aged employees being not interested enough in improving the efficiency of their work. In further research works, it is expected to study the dependence of computer literacy of older adults and their thriving in professional activity, as well as possibilities available for stimulating them to expand their opportunities and improve their welfare.

Very important conclusions concerned the conditions of acquiring the skills of working with the computer. Recommendations can involve improving the teachers' expertise and developing special video courses and lecture cycles using the methods of visualization of the material under study. This is especially important for the elderly who need playing back the lecture materials repeatedly in their independent training. The entire range of software products has to be developed that help increase the efficiency of learning in older adults. These can be gaming software for practicing the skills in professional activity or obtaining the information on some relevant legal advice questions, or working on the state services website, ordering railway and air tickets, searching for the necessary information of cultural and leisure nature. The research has shown that senior citizens are especially concerned about the possibility of making mistakes in the Internet, which limits their experience greatly. The development of simulator or gaming programs can help essentially remove the barriers and alongside with that enhance the level of their independence in all kinds of life activity and boost their self-esteem, too.

Experience shows that senior citizens are especially keen on various information connected with the questions of medicine and healthcare. However, the Internet is well known to be full of fake programs, broadcasts and untrustworthy information on the topic that can do a considerable harm to the aged. IT and mastering the fundamentals of computer literacy implies acquiring the skills of checking validity of the information found. 
Alongside with that, expert evaluations of social work specialists and computer literacy teachers have shown that the Russian educational environment has almost no IT and teaching technologies targeted at the elderly. So preparing such software products is a good task for specialists. Given the retirement age increase in Russia and expanding large-scale learning programs for senior citizens, these developments and software products will enjoy a keen demand.

Improvement of the older adults' information literacy gains different forms in all countries. Studying the experience of various countries allows rendering the work more efficient.

Boosting the interest in using the Internet resources, communicating via social networks, using computers in various life activities is the pivotal basis for solidarity in in the contemporary society, for continuity of generations and development of the knowledge society, as well as for bridging the information gap and improving the welfare of older adults in the society.

\section{REFERENCES}

Akhtyan, A. G., Anikeeva, O. A., Sizikova, V. V., Shimanovskaya, Ya. Y., Starovoitova, L. I., Medvedeva, G. P., \& Kozlovskaya, S. N. (2018). Information literacy of older people: social aspects of the problem. International Journal of Civil Engineering and Technology, 9(11), 1789-1799.

Anikeeva, O. A., Sizikova, V. V., \& Fomina, S. N. (2017). Social aspects of educational needs of the older generation citizens. CITISE, 4(13). Retrieved from http:/ / ma123.ru/ru/journal/\%D1\%86\%D0\%B8\%D1\%82\%D0\%B8\% D1\%81-\%D1\%8D-\%E2\%84\%96-413-2017

Arnett, J. J. (2011). Emerging Adulthood(s): The Cultural Psychology of a New Life Stage. J. J. Arnett (Eds.). Bridging Cultural and Developmental Approaches to Psychology: New Synthesis in Theory, Research, and Policy. Oxford: Oxford University Press. https:/ / doi.org/10.1093/acprof:oso/9780199757176.001.0001

Aslanova, O. A. (2011). Social well-being of the aged in the contemporary information society. Society and law, 4(36), 303-312.

Azarina, M. S., Bulozerskikh, S. N., \& Venevtseva, Yu. (2011). Computer technologies in the process of university learning of older adults of the "third age". Digital journal "Original research". Retrieved from http:/ / ores.su/index.php/2011-02-13-16-16-51/21--3-2011-/115

Bogdanovskaya, V. I. (2014). Information learning of the third-age people: a promising focus area of their active life stance. Collections of conference works by Sociosphere SPC. Retrieved from http://www.sociosphera.com/publication/conference/2014/220/informacionnoe_obuchenie_pozhilyh_1 yudej_perspektivnoe_napravlenie_ih_aktivnoj_zhiznennoj_pozicii/

Bowling, A. (2007). Aspirations for Older Age in the 21st Century: What is Successful Aging? International Journal of Aging and Human Development, 64, 263-297. https:/ / doi.org/10.2190/L0K1-87W4-9R01-7127

Chigisheva, O. (2018). Functional literacy: Terminological ambiguity in the worldwide educational context. Astra Salvensis, 6, 963-970.

Firsov, M. V., \& Shimanovskaya, Ya. V. (2018). Practice of social work in the contemporary global world: crossroads of cultures and time. Moscow: Publishing house of RSSU.

Gasanov, M. A. (2015). Emotional status and network welfare of older adults in Russia. Advances in current natural sciences, 1, 521-527.

Gavrilyuk, V. V., Sorokin, G. G., \& Farakhutdinov, Sh. F. (2009). Functional illiteracy in conditions of the transition to information society. Tyumen: Tyumen University.

Horrigan, J. B., Rainie, L., \& Page, D. (2016) Life Long Learning and Technology / Online. Retrieved from https://www.pewresearch.org/wp-content/uploads/sites/9/2016/03/PI_2016.03.22_Educational-Ecosys tems_FINAL.pdf

Ilyina, I. Yu., Shpilina, T. M., Kalmykov, S. B., Rudnev, V. D., \& Maloletko, A. N. (2017). Integrated assessment of the efficiency of activity of the employment service bodies in the current social and economic conditions. Report on scientific research work No. GK 17-K-16-152 dated 07.07.2017. Moscow: Ministry of Labor and Social Protection of the Russian Federation.

Ismaghilova, G. K., \& Nabiullina, E. R. (2017). IT in education. International scientific journal "Innovation science". No. 04-2. Kazan: KFU.

Kohli, M. (2005). Generational changes and generational equity. The Cambridge handbook of age and ageing. Cambridge: Cambridge University press. https://doi.org/10.1017/CBO9780511610714.056 
Komp, K., \& Van Tilberg, T. (2010). Ageing societies and the welfare state: where the intergenerational contract is not breached. International Journal of Ageing $\mathcal{E}$ Later Life, 5(1), 7-11. https://doi.org/10.3384/ijal.16528670.10517

Kondratov, B. F. (2009). The "third age" and the Internet. Information society. Moscow: Ministry for Public Health and Social Development of the RF. Retrieved http:/ / emag.iis.ru/arc/infosoc/emag.nsf/BPA/11683e3292f61-ae2c3257594003ec081

Kozlovskaya, S. N., Sizikova, V. V., Anikeeva, O. A., \& Shimanovskaya, Ya. V. (2018). The personnel training's innovative technologies for the social protection of the population. Opcion, 34, 870-888.

Kuzmin, E. I., \& Parshakova, A. V. (2017). Media- and information literacy in knowledge societies. Moscow: Interregional center for cooperation of libraries (MCBS).

Mamedova, K. A. (2016). IT as an essential component of the system of education // Universum: Psychology and Education: digital scient. Journal, 9(27), 118-126. Retrieved on 30.03.2019 from http://7universum.com/ru/psy/archive/item/3-526

Marson, S. (2013). Editorial: Is Infantilization Ethical? An Ethical Question. Journal of Social Work Values E Ethics, 10(1), 11-24.

Marson, S. M., \& Powel, R. M. (2014). Goffman and the Infantilization of Elderly Persons: A Theory in Development. Journal of Sociology \& Social Welfare, 17(4), 143-158.

Mcnamara, T., \& Williamson, J. (2004). Race, Gender, and the Retirement Decisions of People Ages 60 to 80 : Prospects for Age Integration in Employment. International journal of aging $\mathcal{E}$ human development, 59, 255-286. https:// doi.org/10.2190/GE24-03MX-U34P-AMNH

Miklyaeva, A. (2018). Infantilization of the elderly in daily interaction: on the problem statement. Journal of social policy studies, 16(1), 109-124. https:/ / doi.org/10.17323/727-0634-2018-16-1-109-124

Moody, H. R. (2001). Productive ageing and the ideology of old age. Baltimore: Johns Hopkins.

Morozova, A. A. (2012). Criteria for assessing the population's media literacy: online testing. Economic, legal and sociocultural aspects of development of regions: a coll. of scient. works. Chelyabinsk: Chelyabinsk University.

Moulaert, T., \& Biggs, S. (2013). International and European Policy on Work and Retirement: reinventing critical perspectives on active ageing and mature subjectivity Human Relations. https:/ / doi.org/10.1177/0018726711435180

Naumov, R. A. (2015). On computer literacy of older adults. Social work, 4, 35-37.

Pashchenko, O. I. (2013). Information technologies in education: a study guide. Nizhnevartovsk: Publishing house of Nizhnevartovsk State University.

Podolskiy, O. A., Popov, D. S., \& Rylko, E. D. (2015). How competent adult Russians are at present? Results of the Program for the International Assessment of Adult Competencies (PIAAC) in the Russian Federation. National research university "Higher School of Economics", the Institute of education. Moscow: NRU HSE.

Salimyanova, Z. R. (2013). Computer literacy and information culture in people of the third age. Relevant questions of the current pedagogy: materials of the $4^{\text {th }}$ International scient. conf. Ufa: Leto, pp. 214-217.

Smolkin, A. A. (2012). Skills of the contemporary computer technologies mastery in representatives of the older age groups as a condition for their successful social and economic integration. Sociology of power, 7(1), 168-172. Retrieved from http:/ / socofpower.rane.ru/uploads/6-7(2012)/10.pdf

Vladimirov, D. G. (2015). Senior citizens at the labor market: the foreign experience. Retrieved from http://www.isras.ru/files/File/Socis/2013-6/Vladimirov.pdf

\section{http://www.ejmste.com}

